\title{
ADA APA DENGAN SUPERVISI PENDIDIKAN?
}

\author{
ERMI SOLA \\ Fakultas Tarbiyah dan Keguruan UIN Alauddin Makassar \\ Jl. HM. Yasin Limpo No. 36 Makassar \\ Email: eminpatta@gmail.com
}

\begin{abstract}
Education, in a simply meaning is making human being human, done through the process of learning. This process includes organizing to organize the environment of the class that will influence to their motivation of learning. In this case, the teacher is the main star to reach the goal of the meaningful learning. Among those activites the teachers should go through is supervision. Educational supervision is a service or an assistance given by the supervisor to the teachers in order to improve the quality of teaching and leaning, or a better teaching and learning situation. The principal at school is the supervisor for the teachers at school. The principal holds an important function in helping the teachers to improve their competencies and professionalism as well. In some schools, the supervisor make hard efforts to do their responsibility as supervisors, however, the result is still far from what it is expected. There is an image that the presence of the supervisor is just like a "monster" for the teachers. It is because of the attitude of the supervisor, such as insists his willingness, finds the teacher's mistake, arrogant, and the other negative attitudes. These negative attitudes make the teachers feel inferior, powerless. This condition will contribute to a negative influence on the teacher's motivation in exploring their creativity in teaching.
\end{abstract}

Keywords: Education, Teaching and Learning

\section{PENDAHULUAN}

$\mathrm{P}$ endidikan yang secara sederhana bermakna memanusiakan manusia, secara detail proses perubahan sikap dan tata laku seseorang atau kelompok orang dalam usaha mendewasakan manusia melalui upaya pendididkan dan pengajaran, dan pelatihan. Pendidikan dapat dilakukan melalui jalur dan jenjang pendidikan yang bertahap dan terorganisir baik formal, non formal, maupun informal dan berjenjang, dimulai dari pendidikan dasar hingga pergurun tinggi.

Menurut UU RI no. 20 tahun 2003 tentang Sistem Pendidikan Nasional mengamanatkan bahwa pendidikan merupakan usaha sadar dan terencana untuk mewujudkan suasana belajar dan proses pembelajaran agar peserta didik secara aktif mengembangkan potensi dirinya untuk memiliki kekuatan spiritual keagamaan, pengendalian diri, masyarakat, bangsa dan negara. 
Dalam hal ini, guru merupakan tokoh utama tercapainya pembelajaran yang bermakna. Kehadiran guru dalam kelas dengan semua aktivitas yng melibatkan dirinya dan semua peserta didik akan mewarnai keberhasilan maupun kegagalan proses belajar mengajar.

Di antara aktivitas yang harus dijalani para guru adalah pelaksanaan supervisi. Supervisi secara konseptual merupakan usaha mencapai hasil yang diinginkan dengan cara mendayagunakan bakat/kemampuan alami manusia dan sumbersumber yang memfasilitasi. Upaya tersebut dilakukan dengan cara pemberian tantangan dan perhatian yang serius terhadap bakat/kemampuan alami manusia (Mulianto, dkk., 2006: 3). Dari sisi pendidikan dapat dipahami bahwa supervise pendidikan merupakan usaha dan atau layanan pemberian bantuan pembinaan yang diberikan oleh supervisor kepada para guru dalam upaya meningkatkan kualitas pembelajaran. Kepala sekolah, merupakan supervisor bagi para gurunya. la memegang peranan penting dalam membantu para guru untuk meningkatkan kemampuan dan profesionalitas mereka. Namun, meski beberapa kepala sekolah dalam kapasitasnya sebagai supervisor telah berupaya melakukan tugas dan tanggung jawabnya dalam kegiatan supervisi kepada para guru, hasilnya masih jauh dari yang diharapkan. Adanya kesan bahwa kehadiran supervisor merupakan momok yang menakutkan bagi para sebagian guru, lebih dikarenakan sikap superior supervisor yang memaksakan kehendak, mencari-cari kesalahan, arogan, dan sikap negative lainnya. "Stigma negatif " tersebut menjadikan guru merasa inferior, tidak berdaya. Kondisi ini pada gilirannya akan berdampak negative pada motivasi para guru dalam mengembangkan kreativitas mereka dalam proses pengajaran.

\section{SUPERVISI PENDIDIKAN}

\section{Pengertian Supervisi Pendidikan}

Pelaksanaan supervisi atau pembinaan memiliki peran yang cukup penting yang seharusnya ada di setiap organisasi. Secara operasional, badan kajian dan pengembangan pendidikan dan kebudayaan menyatakan bahwa supervise merupakan usaha yang dilakukan dalam rangka memberikan kesempatan kepada para guru untuk mengembangkan diri dan kemampuannya secara professional (Tim dosen AP UPI, 2011: 313). Artinya, supervise bermakna pada pemberian 
layanan pembinaan kepada para guru yang pada tujuan akhirnya membawa perbaikan pada situasi pendidikan secara umum, dan peningkatan kualitas proses belajar menjagar secara khusus. Supervisi dilakukan di setiap lini organisasi, termasuk organisasi di dalam ranah pendidikan, dalam hal ini sekolah. Kepala sekolah merupakan atasan di dalam lingkungan sekolah. Kepala sekolah memiliki peran strategis dalam memberi bantuan kepada para guru dalam memotivasi merreka ke arah usaha mempertahankan suasana belajar mengajar yang lebih baik. Proses pembelajaran yang berlangsung di kelas tidak selamanya memberikan hasil yang sesuai dengan yang apa yang telah direncanakan dan dituangkan dalam bentuk satuan acara pembelajaran. Ada saja kekurangan dan kelemahan yang dialami selama proses pembelajaran berjalan. Untuk mengatasi keadaan tersebut, dan terlebih jauh tidak berlarut-larut, maka supervisi dapat dilaksanakan oleh kepala sekolah yang berperan sebagai supervisor (Mulyasa, 2004:111). Dalam hal ini, pelaksanaan supervise tidak untuk mencari kesalahan dan atu kelemahan guru dalam mengajar. Supervisi yang dilakukan oleh kepala sekolah yang berperan juga sebagai supervisor pada dasarnya adalah proses pemberian layanan bantuan kepada guru untuk memperbaiki proses belajar mengajar dalam kelas-kelas yang beragam karakter peserta didiknya, dalam upaya meningkatkan kualitas hasil belajar. Kepala sekolah dalam perannya sebagai supervisor harus melaksanakan tugasnya tersebut dengan cara-cara atau teknik-teknik yang mendidik, dengan memperhatikan karakter guru yang disupervisi, sehingga tujuan pemberian supervisi dapat dicapai dengn maksimal.

\section{Fungsi Supervisi Pendidikan}

Secara konseptual, Priansa, dkk (2014: 88) menjelaskan tentang fungsifungsi kepala sekolah sebagai seorang supervisor, yaitu:

1) Fungsi penelitian; fungsi ini bertujuan guna mendapatkan gambaran yang jelas dan objektif tentang situasi pendidikan, khusus dalam aspek supervise, dengan melakukan penelitian. Dalam hal ini, penelitian yang dilakukan melalui tahap-tahap penelitian secara umum, antara lain; perumusan masalah berkenaan dengan focus penelitian, pengumpulan data, pengolahn dan analisis data yang telah 
dikumpulkan, dan kesimpulan. Hasil penelitian digunakan untuk perbaikan proses kegiatan pembelajaran di kelas.

2) Fungsi penilaian: Fungsi penilian merujuk kepada evalausi hasil penelitian yang telah dilakukan sebelumnya, baik positif maupun negative. Artinya, fungsi penilaian bertujuan untuk mengetahui apakah penelitian yang telah dilakukan berkenaan dengan supervisi menggambarkan nilai-nilai positif, sehingga patut untuk ditingkatkan atau justru sebaliknya, menggambarkan nilai-nilai negatif yang menunjukkan kelemahan supervisi sehingga perlu dilakukan perbaikan.

3) Fungsi perbaikan: Fungsi ini merupakan kelanjutan dari fungsi penilaian. Hal ini bermakna bahwa ketika penelitian menunjukkan hasil yang rendah maka diperlukan perbaikan dalam kegiatan supervise. Perbaikan tersebut dilakukan dengan cara mengidentifikasi berbagai kelemahan atau kekurangan dalam pelaksanaan kegiatan supervise. Kemudian mengklasifikasikan masalah, mulai dari yang sederhana sampai kepada yang tersulit. Beranjak dari kedua prosedur, identifikasi dan klasifikasi masalah, barulah dilakukan perbaikan.

4) Fungsi peningkatan: Fungsi ini lebih mengacu kepada hasil penelitian (poin 1) yang menunjukkan hasil positif. Artinya pelaksanaan kegiatan supervise perlu ditingkatkan secara berkesinambungan dan terarah, sehingga tujuan pelaksanaan kegiatan supervise dapat dicapai dengan maksimal.

Dalam hal pelaksanaan kegiatan supervisisi, seorang supervisor memiliki peran penting yang turut berpengaruh kepada kinerja para guru dalam proses pembelajaran di kelas. Di antara peran-peran tersebut adalah:

\section{Perencanaan}

Untuk mencapai keberhasilan dalam melakukan tugasnya sebagai supervisor, kepala sekolh harus membuat rencana yang matang, termasuk memetakan kualifikasi kesuksesannya dalam mensupervisi para guru. Rencana harus dibuat secara rinci, mulai dari yang sifatnya umum sampai yang khusus sehingga akan memudahkan kepala sekolah dalam pencapaian target tugasnya. Hal lain yang penting diperhatikan adalah keterbatasan waktu kepall sekolah dan para guru 
ERMI SOLA

dalam pelaksanaan kegiatan supervisi karena alokasi waktu yang tidak cukup dapat mempengaruhi pencapaian target kesupervisian kepala sekolah.

\section{Pengorganisasian}

Karena begitu banyak kegiatan yang harus diselesaikan kepala sekolah, termasuk sebagai supervisor bagi para guru, maka pengorganisasian orang, tugas, waktu dan fasilitas wajib dilakukan jika tidak ingin pelaksanaan kegiatan supervisi mengalami kegagalan. Secara rinci, kepala sekolah harus mengatur jadwal kegiatan supervise secara rapi terkait guru-guru yang akan disupervisi, kapan akan melakukan supervise, di mana supervise akan dilakukan, hingga supervise jenis mana yang akan dilakukan. Hal ini bermanfaat akan pelaksanaan kegiatan supervise tidak berbenturan dengan kegiatan-kegiatan dan tanggung jawab kepala sekolah lainnya.

\section{Implementasi}

Implementasi merupakan pengejawantahan atau perwujudan dari rencana matang yang telah dibuat dengan pengorganisian tugasnya secara rapi dan rinci. Pada tahap ini, kepala sekolah sejatinya harus membuat scenario implementasi yang bersesuaian dengan rencana yng telah dibuat. Selama proses implementasi, supervisor pengawasan sehingga pelaksanaan supervisi tidak keluar dari rencana.

\section{Evaluasi dan pengawasan}

Setelah tahap pertama hingga ketiga telah dilakukan, supervisor harus melakukan evaluasi gun melihat apakah kegiatan supervise berjalan lancar sesuai rencana dan menuju arah yang tepat, yakni tercapainya target. Jika ternyata kegiatan supervise tidak memenuhi harapan, supervisor harus merumuskan ulang kegiatan supervise berikutnya dengan scenario yang lebih tepat. Namun, apapun hasil supervise, kepala sekolah wajib mengkomunikasikannya dengan para guru.

Mulyasa (2005: 111) mengemukakan beragam fungsi kepala sekolah, termasuk dalam peranannya sebagai supervisor. Fungsi-fungsi tersebut adalah: 
1. Kepala sekolah sebagai edukator

Sebagai seorang educator/pendidik, kepala sekolah merupakan salah satu pelaksana dan pengembang kurikulum di sekolah. Kepala sekolah yang merupakan ujung tombak penggerak bagi para guru dan persionalia lainnya di sekolah harus memiliki komitmen yang tinggi demi tercapainya tujuan-tujuan pendidikan dan pembelajaran di sekolahnya. Kepala sekolah juga harus memperhatikan kompetensi para guru yang berbeda satu dengan yang lainnya, sehingga pembinaan yang akan diberikan dapat berjalan secara optimal sesuai rencana telah dibuat dan target yang ingin dicapai.

\section{Kepala sekolah sebagai manager}

Manajemen sebagai "the process of getting activities completed" (Robbins and De Cenzo, 1995:4), atau

"the process of attaining organizational goals by effectively and efficiently planning, organizing, leading and controlling the organization's human, physical, financial, and information resources" (Boove, et.al, 1993: 5)

merupakan tugas kepala sekolah sebagai manager pendidikan di sekolahnya. Artinya, kepala sekolah mengelola berbagai kegiatan pendidikan dalam usaha mencapai tujuan pendidikan dan pengajaran, dimulai dari perencanaan hingga pengawasan, dst. Dalam hal ini, mengembangkan profesionalitas para guru merupakan bagian penting yang tidak dapat diabaikan begitu saja. Dalm hal ini, kepala sekolah berkewajiban memberikan keluasan kepada tiap guru untuk mengembangkan potensi diri mereka melalui beragam kegiatan, baik berupa pendidikan maupun pelatihan. Kegiatan-kegitan serupa antara lain; aktif di kelompok MGMP/MGP antar sekolah, baik dalam lingkungan kelurahan atau kecamatan yang sama atau berbeda, undangan mengikuti pendidikan dan atau pelatihn yang bersesuaian dengan mata pelajaran, dan melanjutkan pendidikan ke jenjang yang lebih tinggi. Singkatnya, kepala sekolah sebagai manager di sekolahnya, mengemban 8 tugas sebagaimana dikemukakan oleh Stoner (Wahjosumidjo, 1987:35), yakni: 
ERMI SOLA

“1) the manager assumes responsibility, 2) the manager must balance competing gols, 3) the manager is a conceptual thinker, 4) the manager works with and through other people, 5) the manager is a mediator, 6) the manager is a politician, 7) the manager is a diplomat, 8) the anager makes difficult decisions"

\section{Kepala sekolah sebagai administrator}

Dengan peran yang hampir sama dengan manager, kepala sekolah mengatur berbagai aspek dalam pelaksanaan kegiatan operasional sekolah. Di antaranya mengatur pengelolaan keuangan. Kepala sekolah harus mampu dan cakap mengalokasikan keuangan sekolah dengan berbagai kegiatan yang telah direncanakan, termasuk kegiatan pendidikan dan latihan yang diperuntukkan bagi para guru. Dengan alokasi anggaran yang memadai bagi para guru, dapat dipastikan akan berdampak positif bagi pengingkatan kompetensi dan profesionalitas guru dalam menjalankan tugasnya sebagai pendidik.

\section{Kepala sekolah sebagai supervisor supervisor}

Sebagai supervisor, kepala sekolah membantu dan atau membina para guru dan staf lainnya dalam pelaksanaan tugas dan tanggung jawab masing-masing. Dengan bantuan dan pembinaan dari kepala sekolah, diharapkan para guru dan staf lainnya akan makin cakap dan terampil dalam menyelsaikan tugas dan tanggunng jawab mereka, yang pada gilirannya akan berpengaruh kepada ketercapaian tujuan yang telah ditetapkan. Dalam kaitannya dengan supervise yang dilakukan terhadap para guru, kepala sekolah dapat membuat kesepakatan dengan guru tertentu untuk melakukan kunjungan kelas, mengamati proses belajar mengajar. Hasil kunjungan kelas tersebut didiskusikan guru yang bersangkutan guna mendiskusikan kelebihan dan atau kekurangan selama proses belajar mengajar berlangsung. Dalam melaksanakan kegiatan supervise, kepala sekolah sejatinya adalah orang yang memahami perkembangan kurikulum yang seringkali berubah atua berganti. Tanpa penguasaan kurikulum dengan berbagai aspek yang tercakup di dalamnya secara baik, akan sulit bagi kepala sekolah melaksanakan fungsi supervise dengan optimal. 
5. Kepala sekolah sebagai leader

Kepemimpinan adalah kemampuan memengaruhi (dengan cara apapun) tingkah laku orang lain menuju sasaran tertentu (Mulianto, 2006: 38). Kepala sekolah adalah pemimpin tertinggi di sekolahnya. Tentunya, kepiawaiannya dalam memimpin akan terefleksikan dalam gerak langkah bawahannya dalam pelaksanaan berbagai kegiatan persekolahan. Dalam hal ini, kepala sekolah sebagai leader di sekolahnya sejatinya harus memiliki sifat-sifat antara lain; jujur, percaya diri, bertanggung jawab, berani mengambil keputusan berikut resiko yang mengiringinya, berjiwa besar, memiliki kestabilan emosi, dan mampu menjadi teladan (Mulyasa, 2005).

6. Kepala sekolah sebagai inovator

Untuk menjalankan fungsinya sebagi inovator, kepala sekolah harus memiliki strategi yang tepat dalam membina hubungan yang harmonis semua orang yang berada di sekolah, dan dengan lingkungan di mana sekolahnya berada. Kepala sekolah juga diharapkan memiliki ide-ide baru bahkan temuan-temuan baru dalam mengembangkan potensi bawahannya, termasuk jika mungkin mengintegrasikan kegiatan-kegiatan yang berbeda namun dalam jenis yang sama/mirip. Inovasi yang dilakukan kepala sekolah berlaku untuk kegiatan kependidikan maupun non kependidikan.

7. Kepala sekolah sebagai motivator

Mulianto (2006:22) merinci karakteristik pemimpin dan bawahnnya terkait motivasi:

a. Memiliki tanggung jawab pribadi yang tinggi,

b. Memiliki program kerja yang terencana dengan sasaran yang jelas dan realistis, dan berjuang untuk merealisasikannya,

c. Memiliki kemampuan dalam pengambilan keputusan dan resiko yang mengiringinya,

d. Melakukan pekerjaan yang bermakna dengan hasil yang memuaskan, 
e. Memiliki keinginan menjadi yang terdepan yang menguasai

Makin banyak, dalam hal ini kepala sekolah, mengenal bawahannya, semakin mampu ia memahami kebutuhan-kebutuhan mereka dan semakin mudah memotivasi mereka untuk melaksanakan tugas dan tanggung jawabnya. Seiring dengan itu, pemberian reward dan atau punishment tetap berlaku jika capaian para guru dan staf lainnya menggembirakan atau mengecewakan.

\section{Tugas dan Tanggung Jawab Kepala Sekolah sebagai Supervisor}

Sebagai supervisor di sekolah, kepala sekolah tanggung jawab memenej dan atau mengatur seluruh aspek kurikulum yang berlaku di sekolah agar dapat berjalan dengan lancar sehingga memberikan hasil optimal sesuai target yang telah ditentukan. (Soetopo dan Sumanto, 1998: 42) menjelaskan bahwa aspekaspek kurikulum meliputi:

1. Membantu guru-guru dalam merencanakan, melaksanakan dan menilai kegiatan program satuan pelajaran.

2. Membantu guru dalam menyusun kegiatan ajar mengajar.

3. Membantu guru dalam menilai proses dari hasil belajar-mengajar.

4. Membantu guru dalam menilai hasil belajar siswa.

5. Membantu guru dalam menterjemahkan kurikulum ke dalam pengajaran.

Neagley, (Pidarta, 1997: 67) mengemukakan 10 tugas supervisor (duniakampus7.blogspot.com) yakni: 1) Mengembangkan kurikulum, 2) Mengorganisasi pengajaran, 3) Menyiapkan staf pengajaran, 4) Menyiapkan fasilitas belajar, 5) Menyiapkan bahan-bahan pelajaran, 6) Menyelenggarakan penataran-penataran guru, 7) Memberikan konsultasi dan membina anggota staf pengajar, 8) Mengkoordinasi layanan terhadap para siswa, 9) Mengembangkan hubungan dengan masyarakat, dan 10) Menilai pengajaran. Mulianto (2006: 5-6) merinci tugas dan tanggung jawab supervisor sebagai berikut:

1. Memimpin bawahan yang berada di bawah tanggung jawabnya, 
2. Memahami sasaran lembaga dan mengusahakan agar kontribusi dan hasil kerja bawahan menunjang sasaran lembaga,

3. Memberikan informasi kepada atasan, rekan, dan bawahan,

4. Menjaga kekompakan dan menyamakan persepsi dalam pelaksanaan tugas,

5. Mencari dan mengembangkan cara yang lebih baik dalam mencapai sasaran,

6. Melatih bawahan dengan menekankan kerjasama kelompok (meningkatkan kemampuan bekerja dalam kelompok),

7. Membina dan memelihara kelompok,

8. Menerjemahkan atau menjabarkan kebijakan dan peraturan lembaga sebagai pedoman kerja kelompok,

9. Menjalankan peraturan lembaga,

10. Membuat laporan kepada atasan, baik mengenai hasil kerja maupun hal-hal yang perlu diketahui atasan,

11. Mendelegasikan dan menjadwalkan tugas secara adil kepada bawahan dan mengontrol pelaksanaannya,

12. Menekan biaya kegiatan tanpa memengaruhi kulitas hasil.

\section{SIMPULAN}

Secara harfiah, supervise sebagai bagian dari kegiatan administtrasi pendidikan pada dasarnya merujuk kepada tugas atau pekerjaan seorang supervisor yang memiliki kelebihan untuk melihat dan mengawasi pekerjaan orang lain. (super; sifat lebih; hebat dan vision; melihat sesuatu/tingkah/kerja orang lain). Secara konseptual, supervise bermakna pada usaha seorang supervisor untuk mencapai hasil yang diinginkan dengan mendayagunakn bakat/kemampuan alami manusia, dan sumber-sumber yang dapat memfasilitasinya, dengan menekankan pada pemberian tekanan dan perhatian yang sebesar2nya terhadap bakat alami manusia. Artinya, dalam bidang pendidikan, kepala sekolah sebagai seorang supervisor, tidak bekerja/menangani sendiri pelaksanaan tugas kesupervisiannya. 
Tugasnya lebih berfokus pada mengarahkan, membimbing, dan melatih bawahanpendidik dan tenaga kependidikan lainnya--sehingga mereka dapat memberikan kontribusi secara maksimal dalam melaksanakan tugas-tugas kependidikannya. Di samping itu, kepala sekolah sangat perlu menciptakan iklim kerja yang menyenangkan, yang dapat menjadikan bawahannya bekerja dengan tenang dan bersemangat sehingga dapat berpengaruh pada peningkatan kinerja mereka. Lalu,

1. Kenapa masih ada di antara sebagian kepala sekolah melakukan tugas dan fungsi supervisinya dengan cara-cara yng tidak santun, yang berdampak pada keengganan para guru untuk di supervise?

2. Kenapa hasil supervise tidak mempengaruhi kinerja para guru?

3. Kenapa masih ada kesan bahwa supervise yang dilakukan oleh kepala sekolah lebih mirip pada instruksi?

4. Ada apa dengan pelaksanaan supervise di sekolah-sekolah kita?

\section{DAFTAR PUSTAKA}

Boove, et.al 1993. Management. New York: McGraw-hill, Inc.

duniakampus7.blogspot.com/2014/12/tugas-dan-tanggung-jawab-kepalasekolah_30.html?m=1

Mulianto, Sindu, dkk. 2006. Panduan Lengkap Supervisi; Diperkaya Perspektif Syari'ah. Jakarta: PT. Elex Madia Komputindo.

Mulyasa, E. 2005. Menjadi Guru Profesional: Menciptakan Pembelajaran Kreatif dan Menyenangkan. Bandung: PT. Remaja Rosdakarya

Priansa, Doni J, DKK. 2014. Manajemen Supervisi dan Kepemimpinan Kepala Sekolah. Bandung: Alfabeta

Robins, Stephen P., de Cenzo, David A. 1995. Fundamentals of Management; Essential Concepts nd Applications. New Jersey: Prentice-Hall International, Inc.

Soetopo, Hendyat., Soemanto, Wasty. 1988. Kepemimpinan dan Supervisi Pendidikan. Jakarta: Bina Aksara

Tim Dosen Administrasi Pendidikan Universitas Pendidikan Indonesia. 2011. Manajemen Pendidikan. Bandung: Alfabeta

UU RI no. 20 tahun 2003 tentang Sistem Pendidikan Nasional. 